\title{
Equalization Technique for Balancing the Modulation Ratio Characteristics of the Single-Phase-to-Three-Phase Matrix Converter
}

\author{
Vengadeshwaran Velu, ${ }^{1}$ Norman Mariun, ${ }^{2}$ Mohd Amran Mohd Radzi, ${ }^{2}$ \\ and Nashiren Farzilah Mailah ${ }^{2}$ \\ ${ }^{1}$ School of Science and Engineering, Manipal International University, 71800 Nilai, Malaysia \\ ${ }^{2}$ Faculty of Engineering, Universiti Putra Malaysia, 43400 Serdang, Selangor, Malaysia \\ Correspondence should be addressed to Vengadeshwaran Velu; vengadeshwaran.velu@miu.edu.my
}

Received 1 July 2015; Revised 26 December 2015; Accepted 28 December 2015

Academic Editor: Michele Risi

Copyright (C) 2016 Vengadeshwaran Velu et al. This is an open access article distributed under the Creative Commons Attribution License, which permits unrestricted use, distribution, and reproduction in any medium, provided the original work is properly cited.

\begin{abstract}
Three-phase system has numerous advantages over the single-phase system in terms of instantaneous power, stability, and cost. Three-phase systems are not available in every location particularly in remote rural areas, hill stations, low voltage distribution homes, and so forth. Having a system that is capable of converting directly the readily available single-phase system to three phases will have greater usability in various applications. The routine techniques adopted in the direct ac-ac single-phase-to-three-phase converters do not yield the best desired outputs because of their complexity in the segregation process and bidirectional nature of the input signal. Other initiatives use ac-dc-ac converters which are huge and costly due to dc link energy storage devices. Further, none of these systems provide a convincing result in producing the standard three-phase output voltages that are $120^{\circ}$ away from each other. This paper proposes an effective direct ac-ac single-phase-to-three-phase conversion technique based on space vector pulse width modulation based matrix converter system that produces a convincing three-phase output signals from a single-phase source with balanced modulation index characteristics. The details of the scientific programming adopted on the proposed technique were presented.
\end{abstract}

\section{Introduction}

Conversion of single phase to three phases (SP2TP) is always an interesting task in the ac-ac converters sector. Having a converter that takes a single-phase source as an input and produces three phases balanced as output helps to run three-phase loads under single-phase source. Single-phaseto-three-phase matrix converter is one of the most advanced direct ac-ac converters which can be designed for the conversion of the single-phase system to three-phase system. This converter has high prospects in those applications where only single-phase source is available such as home, remote town, and mobile power source. When the ratings of the singlephase induction motor are greater than $0.5 \mathrm{~kW}$, it becomes uneconomical to operate at higher load conditions [1]. Singlephase-to-three-phase converters are widely used in electric locomotives and rural areas where only single-phase power is available due to technical or economic reasons [2]. Conventional single-phase-to-three-phase converters produce unbalanced voltages which have negative effects on the load. The impact of having unbalanced voltages on the induction motor load results in the production of negative sequence voltages which in turn causes excessive losses, overvoltages, mechanical oscillations, and interference with control circuits. Among the various types of converters, conversion of single-phase system to three-phase system is regarded as the most complex one. The major difficulty of such converters is the alternating and bidirectional nature of the input signal which is required to be segregated into three output signals. Advanced scientific programming methods help to solve this complex engineering problem. Matrix converter is designed using the IGBT based bidirectional switches for direct ac-ac 


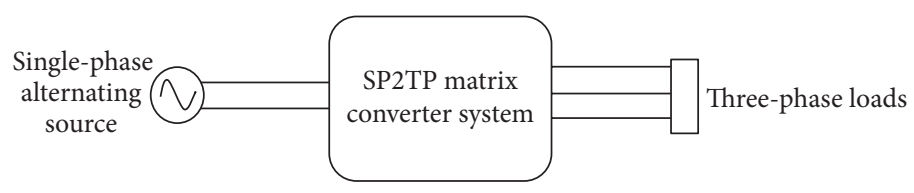

FIGURE 1: SP2TP matrix converter system [9].

conversions. The bidirectional switches are designed in such a way that they should not short-circuit the voltage sources and open-circuit the current sources [3]. On the other hand, the ac-dc-ac converter adopts rectifier-inverter concepts where the single-phase ac voltage is converted to dc voltage in the first stage and in the second inverter stage, the dc voltage is inverted back to three-phase voltages. Despite the THD, losses of ac-dc-ac converter are much lesser compared to direct ac-ac converter; other issues such as additional cost due to bulk storage devices are major drawbacks. Thus, the direct ac-ac converters are more compact in size and cost. For many years, simple carrier based sinusoidal based PWM modulation schemes are used in many applications [4]. However, advance switching algorithm such as space vector based PWM modulation scheme can be employed to segregate the input signal along with the bidirectional IGBT switches based matrix converter to produce the required three-phase output waveforms. Using scientific programming methods, advanced modulation scheme can be implemented using state-of-the-art engineering simulation application and interfacing with the digital signal processor and other control circuits in real time. Space vector pulse width modulation is a unique technique that makes the switching complexity of acac converters much easier. Employing the space vector PWM technique for the single-phase-to-three-phase conversion is the main contribution of the paper. Adjustable speed drives are considered matured due to advances in power semiconductor devices and lower cost. Active devices continue to improve whereas the passive devices such as energy storage capacitor occupy huge system volume, weight, and reliability [5]. Similar research initiative suggests that matrix converter can be operated under buck-boost mode with variable frequencies but under Z-Source topology [6]. Cycloconverters based static converters produced balanced output voltages but suffer from high low order harmonics [7]. Another initiative suggests having two capacitor converters for more balanced operation of induction motor using single-phase supply [8] which are tedious and unreliable. However, all these drawbacks can be overcome by incorporating advance programming techniques based on space vector PWM. This paper provides the design details of the space vector PWM programming based simulation model of the single-phaseto-three-phase matrix converter system and its performance under different load conditions.

\section{SP2TP Matrix Converter System}

Conventionally, the four-quadrant matrix converter uses nine bidirectional switches which are constructed using 18 unipolar turn-off IGBTs and 18 reverse blocking diodes [10].
However, the proposed design only uses six bidirectional switches in the construction of the matrix converter. Figure 1 shows the block diagram of the single-phase-to-three-phase (SP2TP) matrix converter system. The SP2TP system adopts the direct ac-ac conversion technique that converts the singlephase alternating source voltage to three-phase alternating voltages that differ by $120^{\circ}$ from each other. The SP2TP system is designed using six bidirectional switches with two switches being used for each phase.

\section{Design of Matric Converter and Control System}

Space vector pulse width modulation technique can be defined as the combined effect of the three-phase voltages or currents into an equivalent single space vector component derived from all the three-phase quantities at that instant. The derived equivalent vector component is termed as space vector. There are a number of space vector modulation (SVM) techniques available [11]. The ultimate object of the SVM is to produce output voltage and currents nearing unity power factor. However, due to number of hardware limitations, attaining unity power factor becomes more difficult [12]. This paper attempts to describe the most stable and simplest SVM technique for direct ac-ac conversions. Space vector modulation technique adopts the Rotating Magnetic Field theory in which the instantaneous resultant flux of the three alternating fluxes that are $120^{\circ}$ away produces the rotating field at synchronous speed. The theoretical background of the space vector algorithm is given below.

The three-phase sinusoidal currents are represented mathematically as follows:

$$
\begin{aligned}
& i_{a}=I_{m} \sin \omega t, \\
& i_{b}=I_{m} \sin (\omega t-120), \\
& i_{c}=I_{m} \sin (\omega t-240) .
\end{aligned}
$$

In such three-phase system, the three sinusoidal currents produce three sinusoidal alternating fluxes that are equal in magnitude and $120^{\circ}$ away from each other. At the moment when the " $a$-phase" current " $i_{a}$ " carries a maximum value and equals " $I_{m}$ " then the currents in other phases " $i_{b}$ " and " $i c$ " are negative with the magnitudes of

$$
\begin{aligned}
& i_{b}=I_{m} \sin (-30), \\
& i_{c}=I_{m} \sin (-150) .
\end{aligned}
$$

Thus the resultant flux produced by the varying fluxes at any instant is equal to 1.5 times the maximum flux $\left(\phi_{m}\right)$. Considering all instants within a period will yield the condition 


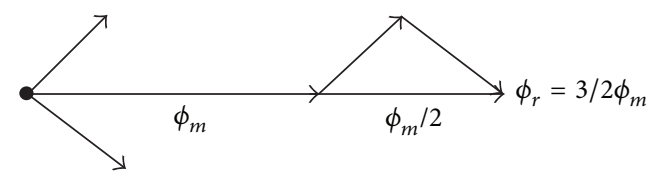

FIgURE 2: Resultant unit space vector.

that the resultant unit vector always equals the value of $1.5 \phi_{m}$ and traces a circle for every period of reference cycle. Figure 2 represents phasor diagram of the resultant flux.

For any three-phase sinusoidal excitations, the maximum flux density produces sinusoidal distribution of fluxes with the maximum values that traces a circle. A similar rotating resultant flux can also be produced using two-phase system where the two voltages are equal in magnitude and differ by $90^{\circ}$ [11]. These fluxes can also be represented as $\alpha$ and $\beta$ components. Superimposing on the three-phase fluxes, the flux produced in the $\alpha$ direction and the flux produced in the $\beta$ direction can be estimated as follows. The ampere-turn produced by the $\alpha$ and $\beta$ components of the resultant flux can be expressed as

$$
\begin{aligned}
& N i_{\alpha}=N i_{a}(t)+N i_{b}(t) \cos 120+N i_{c} \cos 240, \\
& N i_{\beta}=N i_{b}(t) \sin 120+N i_{c} \sin 240 .
\end{aligned}
$$

The $\alpha$ and $\beta$ components of the resultant flux space vector can be expressed in complex form as

$$
N i_{\alpha}(t)+j N i_{\beta}(t)=N\left[i_{\alpha}(t)+j i_{\beta}(t)\right]=N i_{R},
$$

where " $i_{s}$ " is the current reference space vector which can be represented as

$$
i_{R}=\left[i_{\alpha}+j i_{\beta}\right]=\left|i_{R}\right| e^{j \omega t}
$$

Similarly the voltage reference space vector also can be represented as

$$
V_{R}=\left[V_{\alpha}+j V_{\beta}\right]=\left|V_{R}\right| e^{j \omega t+\theta} .
$$

Thus the flux space vector is produced by the current space vector. However, this current space vector is produced by an equivalent voltage space vector [13]. In PWM operation, the average variation is circular. The PWM scheme should be such that the tip of the space vector with the average variation should trace a circle with uniform velocity equal to the input frequency. For any sinusoidal three-phase excitations, the tip of the average value of the space vector of the alternating quantity traces a circle with uniform velocity.

Figure 3 represents the circuit diagram of the singlephase-to-three-phase matrix converter circuit with the bidirectional switches. Each pole will have two states, say 1 and 0. If the top switch is ON, then it is represented as " 1 "; whereas the bottom switch is $\mathrm{ON}$, then it is represented as " 0 ." For each pole there are two states, so for the three phases, there are eight states $\left(2^{3}\right.$ states).

The operating conditions of the 8 states are represented as $000,001,010,011,100,101,110$, and 111 where 000 and 111 are

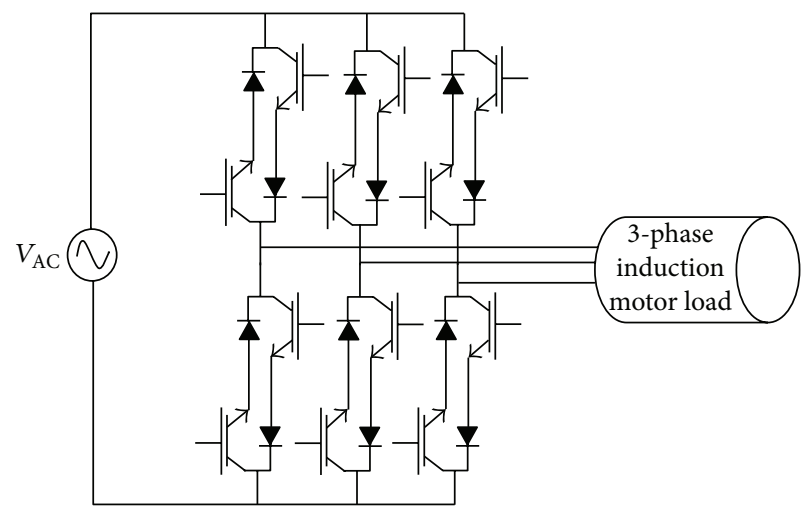

FIGURE 3: Single-phase-to-three-phase matrix converter with bidirectional switches.
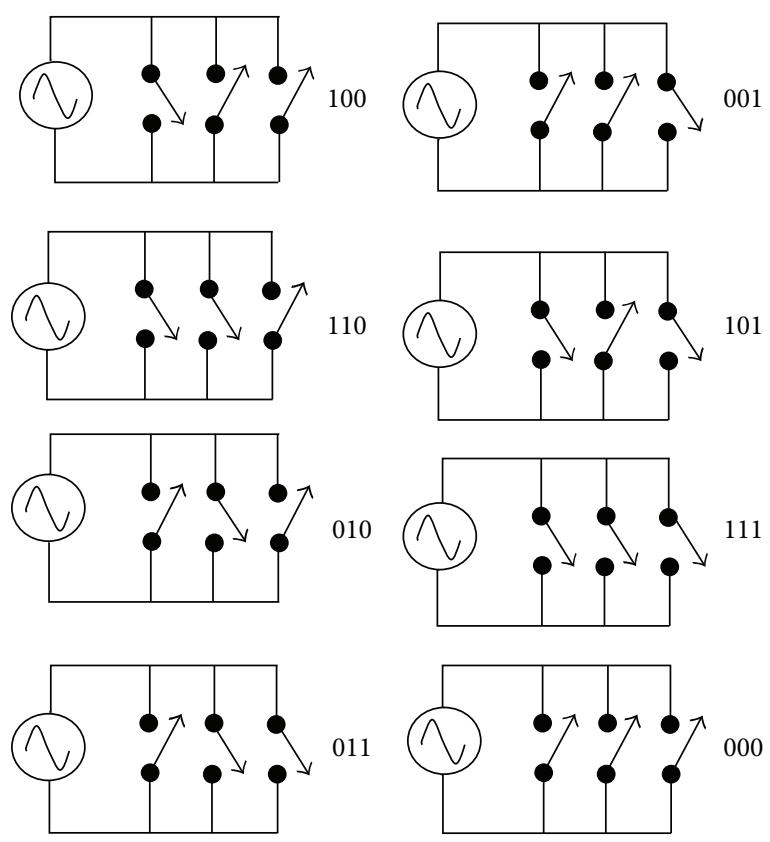

FIGURE 4: Switching states in SVPWM.

zero states; 000 means that all the three bottom switches are $\mathrm{ON}$ and the output terminals are shorted to bottom switches. On the other hand, 111 means that all the three top switches are $\mathrm{ON}$ and the output terminals are shorted to the top switches. The states other than 000 and 111 are active states. The condition of various active states is shown in Figure 4.

Downward arrow represents that the upper switch is closed and bottom switch is open in any particular pole and the upward arrow represents that bottom switch is closed and top switch is open in any particular pole. Similarly, threephase voltages can be represented as a resultant voltage $V_{R}$ that travels in a circle [14]. The circular path is divided into six sectors to represent the six active states. $V_{0}, V_{1}, V_{2}, \ldots, V_{7}$ represent the voltages of the eight possible states between each sector as shown in Figure 5. 


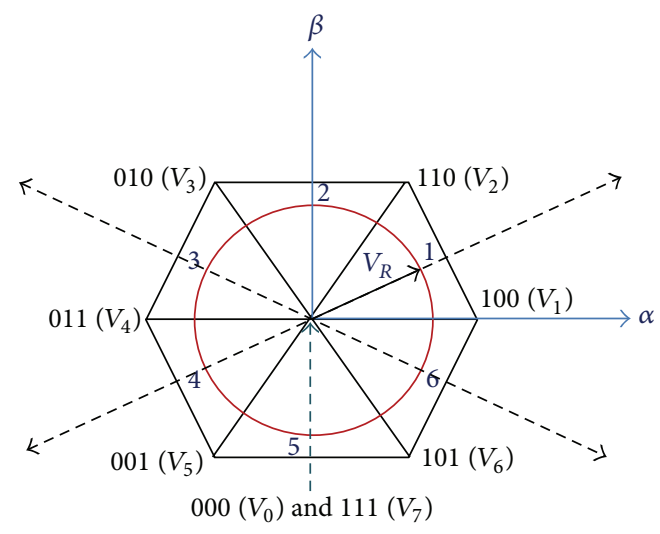

FIGURE 5: Sector representation of space vector modulation.

At any particular moment, the resultant voltage vector $V_{R}$ can be produced by appropriately firing the sector voltages at the given proportional time that depends on the sampling frequency. Sampling time $T_{s}$ is the maximum time allocated to complete the switching of states to produce the particular instant resultant voltage vector. In sector-1, the sequence of triggering would be $V_{0} V_{1} V_{2} V_{7} V_{7} V_{2} V_{1} V_{0}$; however, the sum of the time taken for this triggering sequence should be equal to twice the sampling time [15]. The switching control of the PWM should be programmed in such a way to produce the space vector of voltage which traces a circle with uniform velocity.

The radii of the hexagon are equal to the voltage space vector. For a two-level inverter, all the six active voltage vectors lie along the radii of the hexagon. It is also called as six-step inverter [16]. In order to generate switching sequences, $V_{R}$ should trace the circle with uniform velocity. If $V_{R}$ is in sector-1 and rotating at uniform speed, high frequency sampling signals are used to sample the rotating reference space voltage vector $V_{R}$. Low sampling periods will enhance the quality of the space vector PWM signals. The average value is closest to the sinusoidal. On the other hand, having high frequency will also increase the losses, so an optimum sampling frequency has to be chosen. While sampling, until the next status is reached, the amplitude and angle of $V_{R}$ are assumed to be constant. During that period it switches between the boundary active vectors of the sector and with the zero vectors. The sampling period should be designed such that volt-sec $\left(V_{R}-T_{s}\right)$ balances the required amplitude of the voltage at that particular moment [17]. The components of $V_{R}-T_{s}$ along alpha and beta should be voltsec equal to the volt-sec of active vectors of the particular section and to that of the zero vectors. If $V_{R}$ in sector1 and the boundary voltage space vectors are $V_{1}$ and $V_{2}$, respectively, then the sampling period $T_{s}$ can be represented by

$$
T_{s}=T_{1}+T_{2}+T_{0} \text {, }
$$

where $T_{1}, T_{2}$, and $T_{0}$ are the sampling period for the active vectors $V_{1}$ and $V_{2}$ and the zero vectors, respectively [11].
Generally, the average value of the resultant voltage vector is represented as follows:

$$
\begin{aligned}
\int_{0}^{T_{s}} V_{R} d t= & \int_{0}^{T_{0} / 2} V_{0} d t+\int_{T_{0} / 2}^{T_{0} / 2+T_{n}} V_{n} d t \\
& +\int_{T_{0} / 2+T_{n}}^{T_{0} / 2+T_{n}+T_{n+1}} V_{n+1} d t \\
& +\int_{T_{0} / 2+T_{n}+T_{n+1}}^{T_{s}} V_{7} d t
\end{aligned}
$$

and the sampling time $T_{s}$ is

$$
T_{s}=\left(T_{0}+T_{n}+T_{n+1}\right) .
$$

The average voltage of the zero vectors $\left(V_{0}\right.$ and $\left.V_{7}\right)$ is zero. Thus the fictitious time of the reference voltage vector can be represented as follows:

$$
\left(V_{R} T_{s}\right)=\left[V_{\alpha}+j V_{\beta}\right] T_{s}=\left(V_{n} T_{n}\right)+\left(V_{n+1} T_{n+1}\right) .
$$

By substituting the values of $V_{n}$ and $V_{n+1}$, the reference voltage vector can be represented in the $\alpha \beta$ components as

$$
\begin{aligned}
& \left|\begin{array}{l}
V_{\alpha} \\
V_{\beta}
\end{array}\right| T_{s} \\
& =\frac{2}{3} V_{S}\left[\begin{array}{c}
\cos \frac{(n-1) \pi}{3} \\
\sin \frac{(n-1) \pi}{3}\left|T_{n}+\right| \begin{array}{c}
\cos \frac{(n) \pi}{3} \\
\sin \frac{(n) \pi}{3}
\end{array} \mid T_{n+1}
\end{array}\right], \\
& \left|\begin{array}{l}
V_{\alpha} \\
V_{\beta}
\end{array}\right| T_{s}=\frac{2}{3} V_{S}\left[\begin{array}{cc}
\cos \frac{(n-1) \pi}{3} & \cos \frac{(n) \pi}{3} \\
\sin \frac{(n-1) \pi}{3} & \sin \frac{(n) \pi}{3}
\end{array}\right]\left|\begin{array}{c}
T_{n} \\
T_{n+1}
\end{array}\right|,
\end{aligned}
$$

where " $V$ " is the RMS value of the source input voltage of the converter and $n=1,2,3, \ldots$ represents the sector. The triggering times for the various sectors can be expressed in terms of $\alpha \beta$ components as

$$
\begin{gathered}
\left|\begin{array}{c}
T_{n} \\
T_{n+1}
\end{array}\right|=\frac{\sqrt{3}}{2} \frac{T_{s}}{V_{S}}\left[\begin{array}{cc}
\sin \frac{(n) \pi}{3} & -\cos \frac{(n) \pi}{3} \\
-\sin \frac{(n-1) \pi}{3} & \cos \frac{(n-1) \pi}{3}
\end{array}\right] \\
\cdot\left|\begin{array}{l}
V_{\alpha} \\
V_{\beta}
\end{array}\right| .
\end{gathered}
$$

For any given reference space vector $V_{R}$, corresponding $V_{\alpha}$ and $V_{\beta}$ components can be calculated, from which the duration of the active vectors in the respective sector can be estimated. The ultimate task of segregating the available single-phase waveform into three different waveforms that are $120^{\circ}$ away from each other is achieved through the switching timings estimated from (12). Scientific programming is 

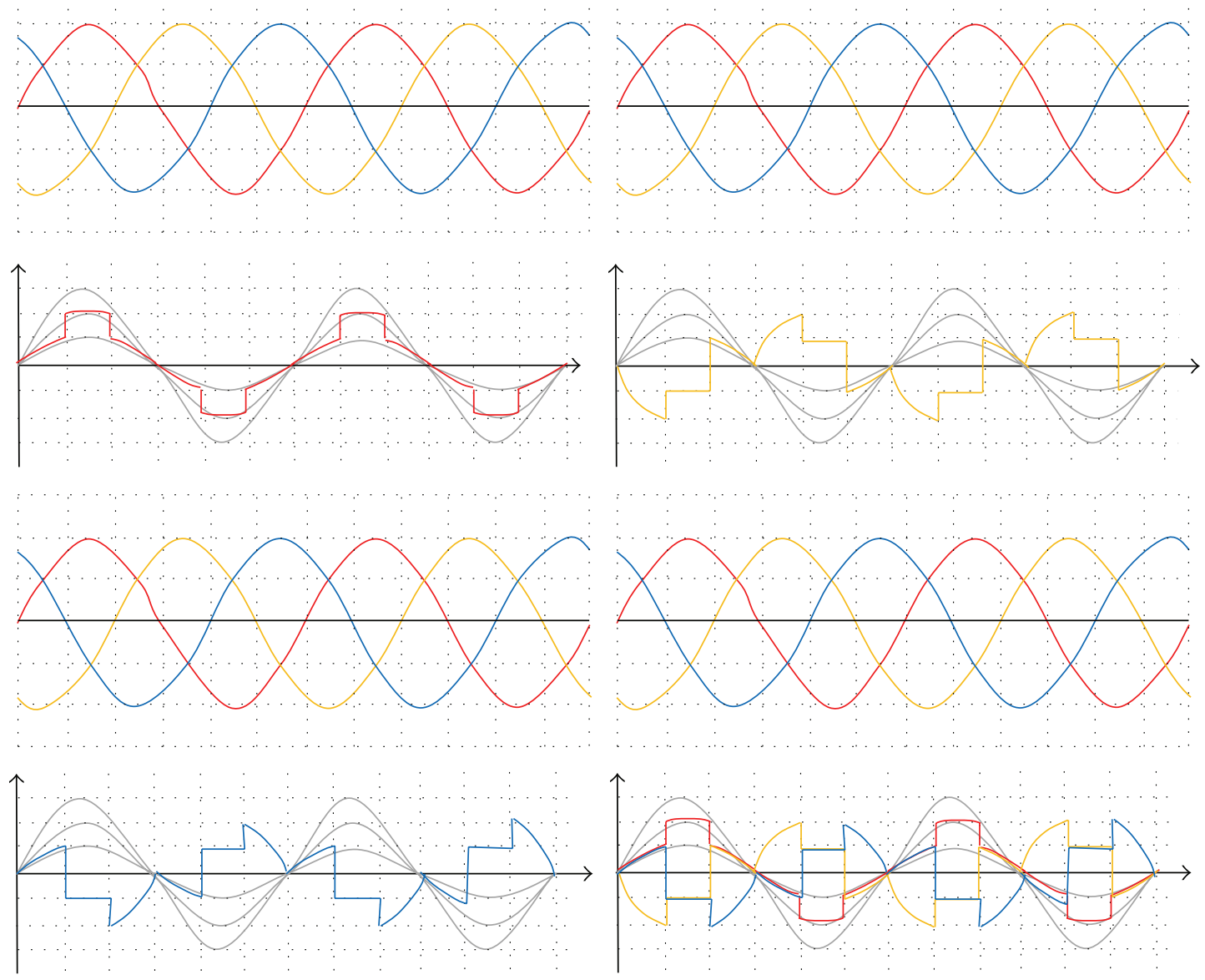

FIGURE 6: Segregation of input signal.

used to produce the triggering pulse durations to turn on the six bidirectional switches appropriately. Figure 6 shows the stages of segregation that takes place at every $\pi / 3$ degrees for all the three phases. At any instant, any one of the phases has $2 / 3$ rd of its maximum value and the other two phases have $1 / 3$ rd of its maximum value in either direction.

\section{Simulation of SP2TP Matrix Converter System}

Matlab/Simulink application is used for the modelling and simulation of the proposed algorithm. The designed Simulink model is then converted into $\mathrm{C}++$ coding for hardware implementation using digital signal processor and IGBT core and driver circuits. Figure 7 shows the various modules of the space vector pulse width modulation section of the converter in which the desired output magnitude, frequency, and the converter input voltage are taken as reference.

The reference three-phase sinusoidal signals are converted to two-dimensional $\alpha-\beta$ components with the sector information. A ramp signal is used for the sampling of space vector at high frequency. According to the sector the switching timing for each bidirectional switch is estimated. There are six PWM signal outputs for the six bidirectional switches of the matrix converter. Table 1 shows the simulation specification of the proposed model of the matrix converter system.

In the Simulink model of the matrix converter circuit, six bidirectional switches are used to construct the matrix converter module. Each bidirectional switch is designed using two IGBTs switched with reversing blocking diodes and the snubber circuits as shown in Figure 8. A three-phase balanced resistive load is used to study the output signals.

\section{Simulation Results of Matrix Converter}

The simulation results of the proposed design are studied for the suitability and implementation for the practical applications. The standard $240 \mathrm{~V}, 50 \mathrm{~Hz}$ single-phase supply is applied as the input to the matrix converter system. Both the space vector modules and the matrix converter modules produce the expected outputs. Figure 9 shows the output phase voltages of the matrix converter system and all the three-phase voltages are $120^{\circ}$ away from each other. The combined waveform resembles the three-phase system waveforms.

Figure 10 shows the output line to line voltages of the matrix converter which are found to be sinusoidal and stable. 


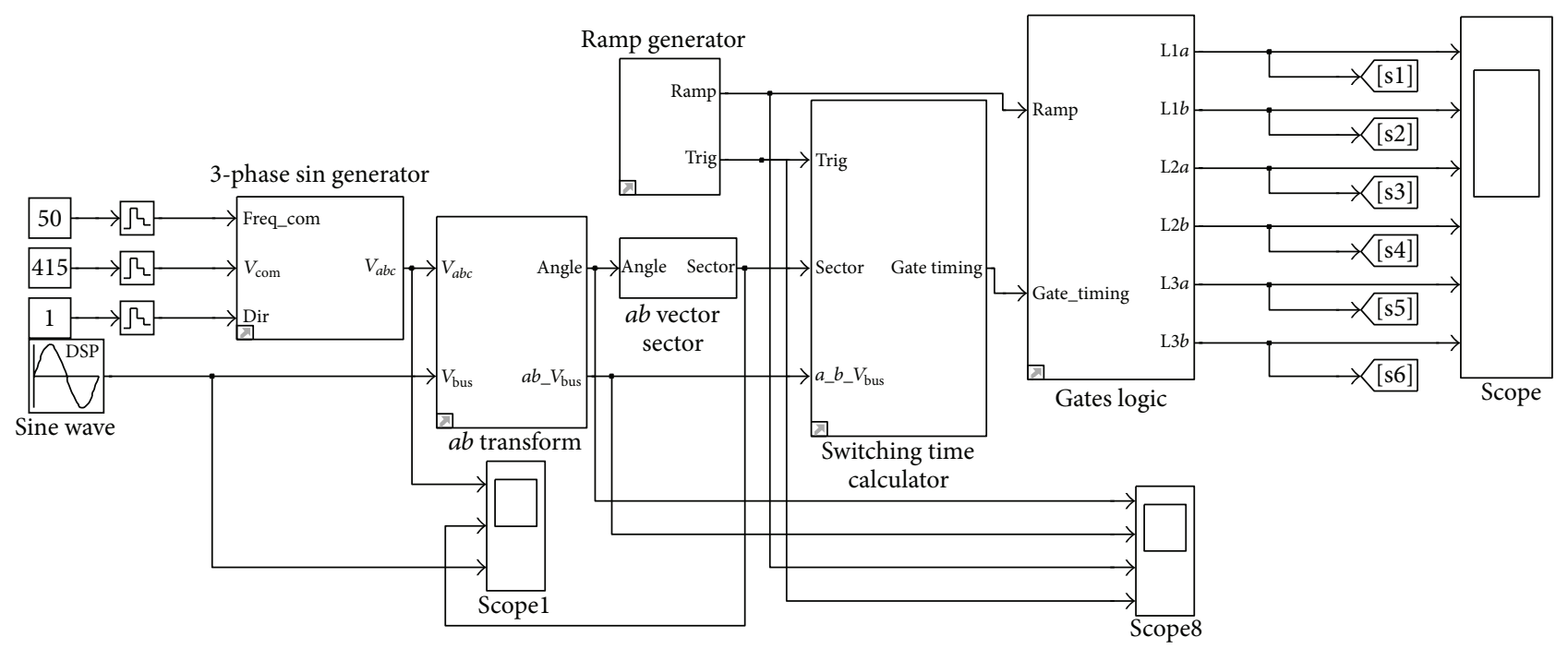

FIGURE 7: Simulation of space vector PWM algorithm for SP2TP matrix converter.

TABLE 1: Simulation parameters of the matrix converter system.

\begin{tabular}{lc}
\hline \multicolumn{2}{c}{ Simulation parameters } \\
\hline Modulation scheme & Space vector PWM \\
Carrier wave & Ramp signal \\
Carrier amplitude $\left(V_{\mathrm{cm}}\right)$ & $1 \mathrm{~V}$ \\
Carrier frequency $\left(f_{c}\right)$ & $4500 \mathrm{~Hz}$ \\
Carrier wave ratio $=\left(f_{c}\right) /\left(f_{r}\right)$ & 90 \\
Modulation index $=\left(V_{\mathrm{rm}}\right) /\left(V_{\mathrm{cm}}\right)$ & 1.0 \\
$V_{\text {ref }}$ amplitude $\left(V_{\mathrm{rm}}\right)$ & Sinusoidal, $1 \mathrm{~V}$ \\
$V_{\text {ref }}$ frequency $\left(f_{r}\right)$ and angle & $50 \mathrm{~Hz}$, zero \\
3-ph ref amplitude & $415 \mathrm{~V}$ \\
3-ph ref frequency \& angle & $50 \mathrm{~Hz}$, zero \\
Number of samples per cycle & 90 \\
Sampling time period $\left(T_{s}\right)$ & $222.2 \mu \mathrm{s}$ \\
Seconds per degree & $0.617 \mu \mathrm{s}$ \\
Number of degrees per sample & 4 \\
Sampling time per sector & $3.33 \mathrm{~ms}$ \\
\hline
\end{tabular}

The combined waveform exactly behaves like a three-phase system voltages.

Figure 11 shows the input and output voltages of the matrix converter under unity power factor load. A star connected balanced resistive network is used as a unity power factor load. The power factor of the input voltage and current is found to be at unity. No phase angle difference is observed between the input and $R$-phase output currents.

Figure 12 shows the input and output voltages of the matrix converter under lagging power factor load. A star connected balanced $R-L$ load is used as a lagging power factor load. The output currents are found to be 120 degrees away from each other and more smoother compared to the resistive load.

In order to determine the appropriate conditions in view of obtaining the balanced output voltages, the simulations
TABLE 2: Output voltages under the effect of varying modulation index at $50 \mathrm{~Hz}$ reference frequency.

\begin{tabular}{lccccc}
\hline 1-ph $V_{S}$ & 1-ph max & $\mathrm{Mi}$ & $V_{a b}$ & $V_{b c}$ & $V_{c a}$ \\
\hline 2541 & 3594 & 0.20 & 2319 & 1611 & 2220 \\
1271 & 1797 & 0.40 & 1159 & 805.2 & 1110 \\
847 & 1198 & 0.60 & 771.9 & 536.4 & 739.4 \\
635 & 899 & 0.80 & 578.9 & 402.3 & 554.6 \\
508 & 719 & 1.00 & 462.7 & 321.5 & 443.3 \\
424 & 599 & 1.20 & 385.2 & 267.7 & 369.2 \\
363 & 513 & 1.40 & 329.7 & 229.1 & 316 \\
318 & 449 & 1.60 & 288.4 & 200.4 & 276.5 \\
282 & 399 & 1.80 & 256.1 & 177.9 & 245.6 \\
254 & 359 & 2.00 & 230.3 & 160 & 220.9 \\
\hline
\end{tabular}

were performed under different modulation indexes. The study on the modulation index characteristics is found to be the vital factor that governs the magnitude of the output voltages. The modulation index of the space vector pulse with modulation can be defined as the ratio of the product of square root times the space vector reference voltage to that of the input supply voltages. The modulation index is expressed as

$$
\text { Modulation Index }(\mathrm{Mi})=\sqrt{3} \frac{V_{\text {ref }}}{V_{S}} .
$$

The RMS values of the output voltages under the effect of varying the modulation index are tabulated in Table 2. Its corresponding modulation index characteristics are shown in Figure 13. The three output voltages are found to be unbalanced. Two of the output voltages are at equal values whereas one of the phases is having relatively low voltage output.

From the modulation index characteristics, it is found that the output line to line voltages are inversely proportional to the modulation index used in the space vector modulation 


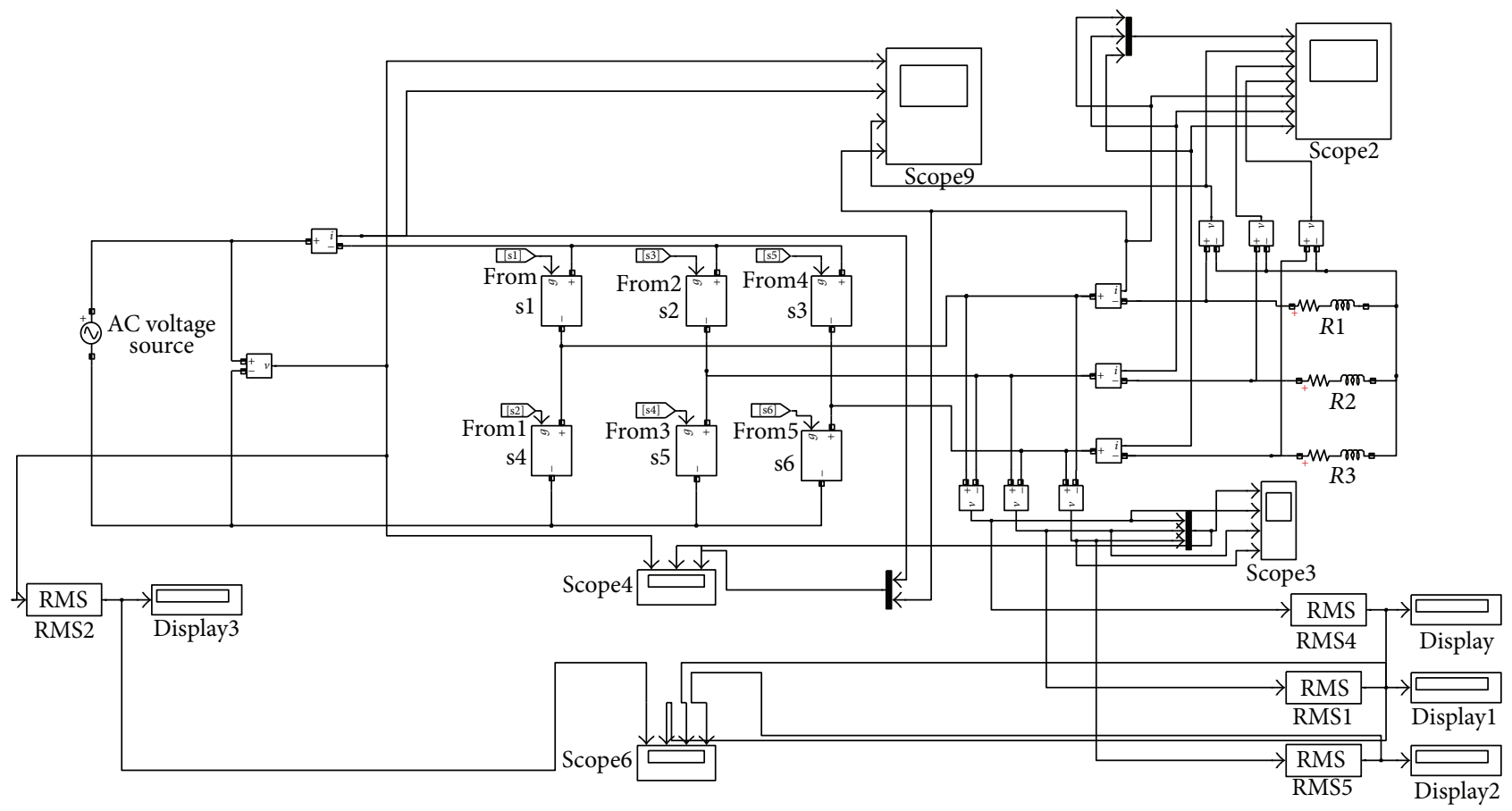

FIGURE 8: Simulation of SP2TP matrix converter with unity power factor load.

TABLE 3: Output voltages under the effect of varying modulation index at $200 \mathrm{~Hz}$ reference frequency.

\begin{tabular}{lccccc}
\hline 1-ph $V_{S}$ & 1-ph max & $\mathrm{Mi}$ & $V_{a b}$ & $V_{b c}$ & $V_{c a}$ \\
\hline 2541 & 3594 & 0.2 & 2090 & 2075 & 2056 \\
1271 & 1797 & 0.4 & 1044 & 1037 & 1027 \\
847 & 1198 & 0.6 & 695.8 & 690.6 & 684.3 \\
635 & 899 & 0.8 & 521.7 & 517.9 & 513.1 \\
508 & 719 & 1 & 417 & 413.9 & 410.1 \\
424 & 599 & 1.2 & 347.2 & 344.6 & 341.1 \\
363 & 513 & 1.4 & 297.1 & 294.9 & 292.2 \\
318 & 449 & 1.6 & 259.9 & 258 & 255.6 \\
282 & 399 & 1.8 & 230.8 & 229.1 & 227 \\
254 & 359 & 2 & 207.5 & 206 & 204.1 \\
\hline
\end{tabular}

algorithm. The lower the modulation indexes, the higher the RMS values of the output voltages. However, the lower modulation index means the higher input supply voltage. So to increase the input voltage, additional step-up transformers are to be used.

The model was studied under wide range of reference frequencies of space vector algorithm. In order to obtain balanced output voltages, the reference frequency of the space vector algorithm has to be increased beyond $150 \mathrm{~Hz}$. When the reference frequency is varied, the simulation model alters the triggering pulses duration and corresponding control signals are produced in the digital signal processors. Thus, the output voltages of the converter are altered correspondingly. Table 3 shows the magnitude of the line to line output voltages of the matrix converter under $200 \mathrm{~Hz}$ operation

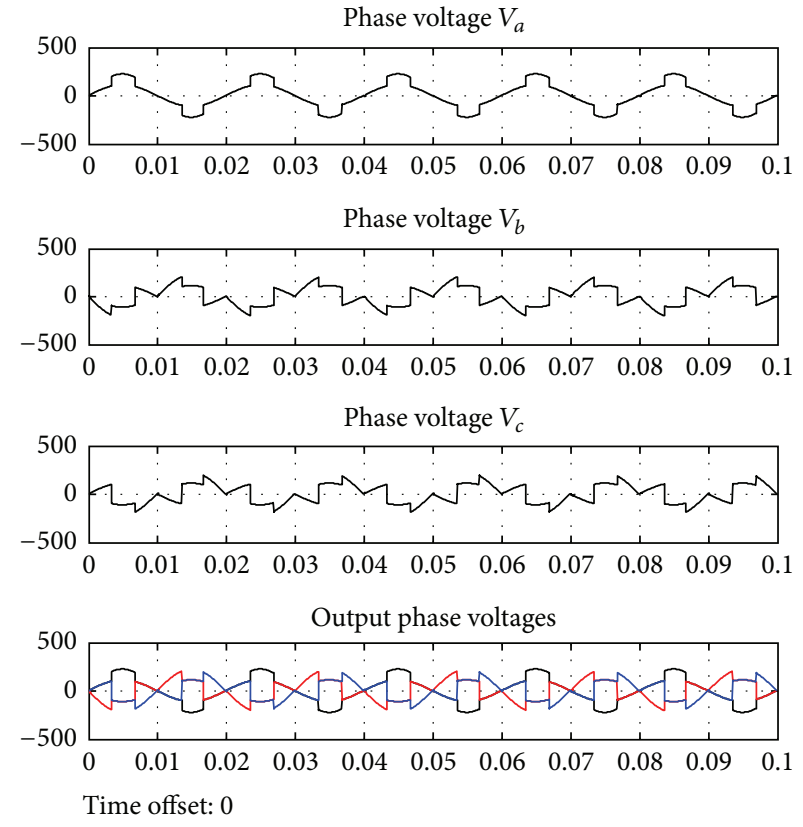

FIGURE 9: Output phases voltages of SP2TP matrix converter with unity power factor load.

and its corresponding modulation characteristics show more balanced output voltages.

The modulation index characteristics obtained with the reference frequency of the program as $200 \mathrm{~Hz}$ are shown in Figure 14. The RMS values of the output voltages are found to be balanced and proportional to each other at all values of modulation index. 

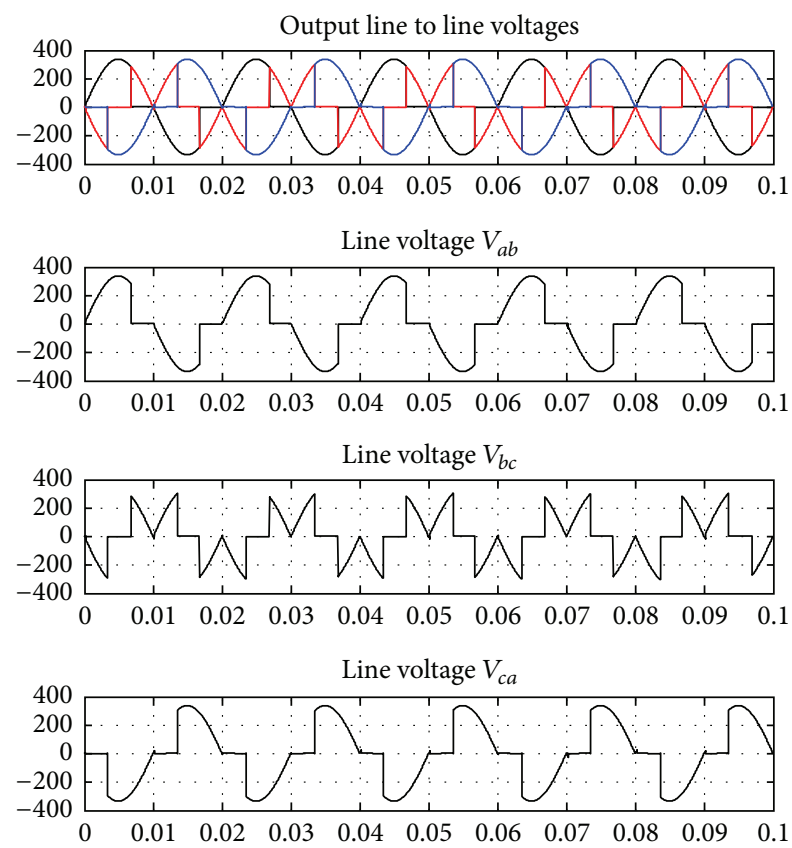

Time offset: 0

FIGURE 10: Output line voltages of SP2TP matrix converter with unity power factor load.
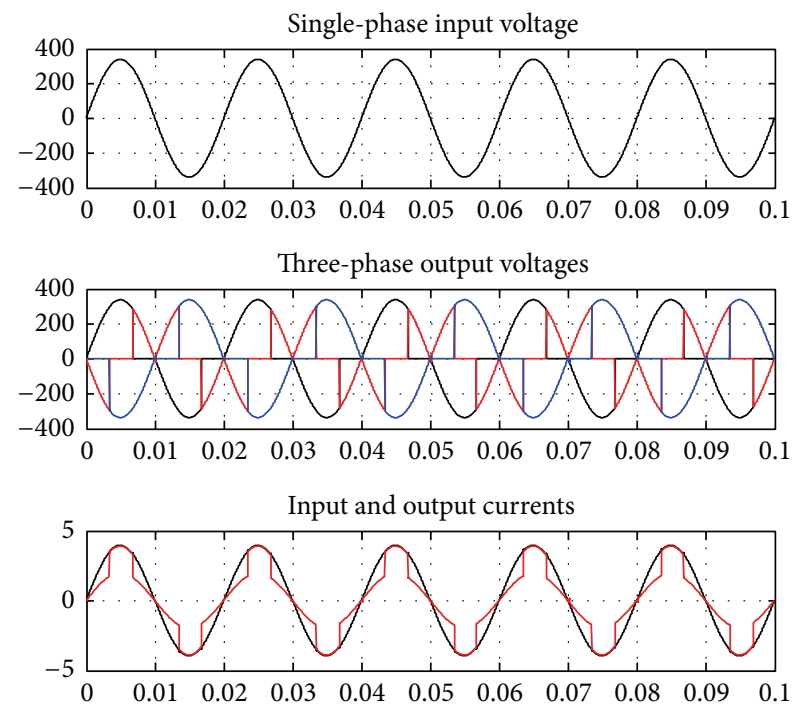

Time offset: 0

FIGURE 11: Voltages and currents under unity power factor load.

Scientific programming model provides more flexibility to choose a wide range of reference frequencies, so that converter can be tuned to generate range of voltages at different frequencies. However it is limited by the hardware realization issues. The appropriate modulated index and reference frequency have to be selected for the desired output voltages of the matrix converter.
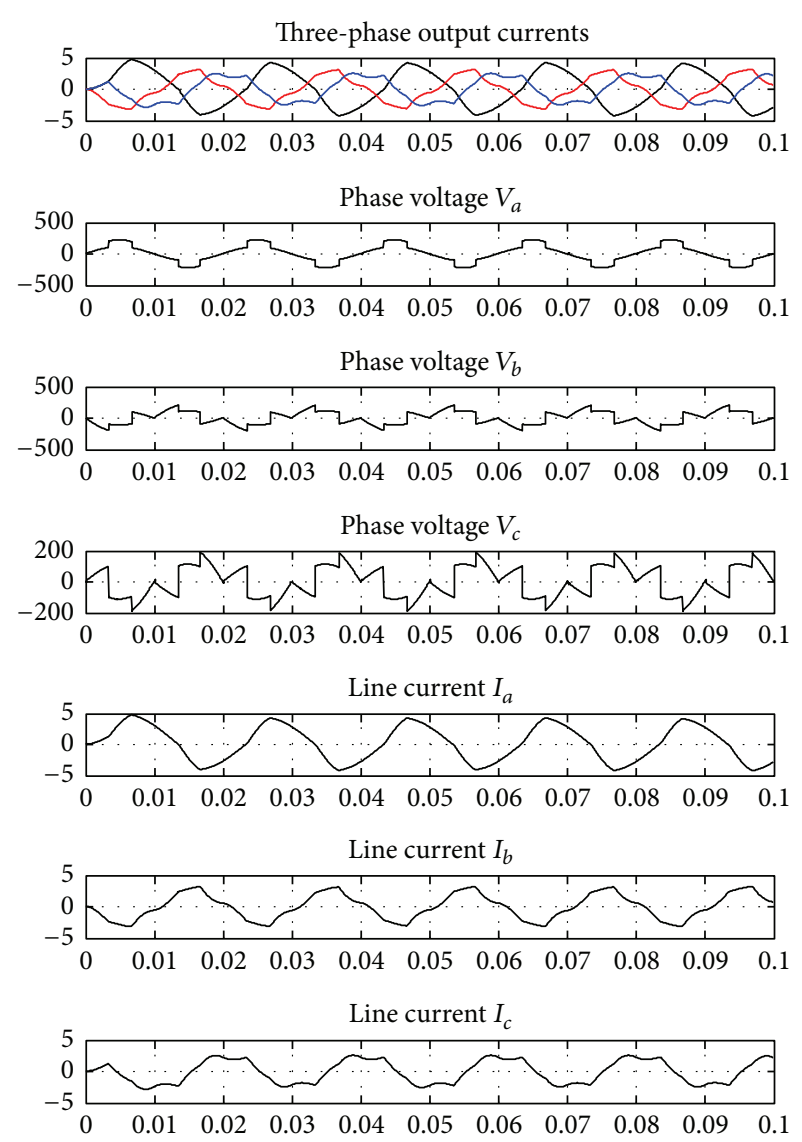

Time offset: 0

FIGURE 12: Voltages and currents under lagging power factor load.

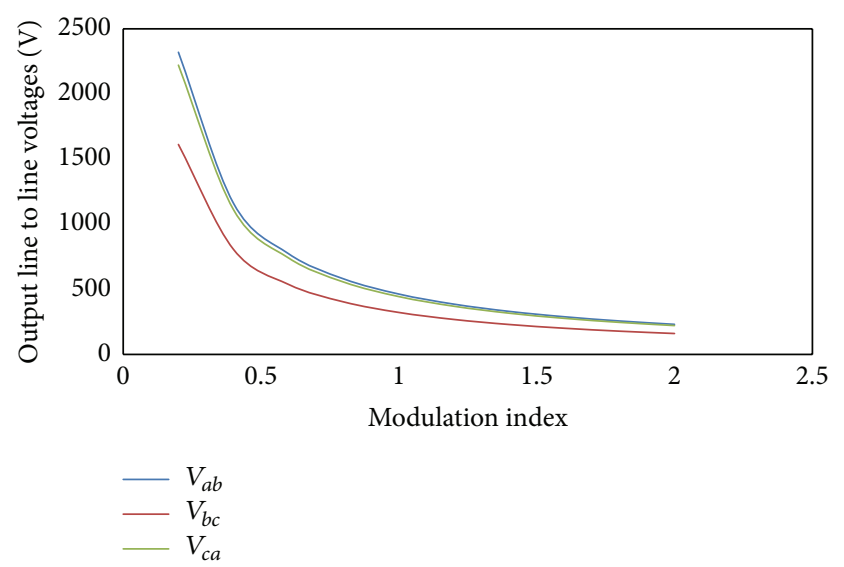

FIGURE 13: Modulation index characteristics at $50 \mathrm{~Hz}$ reference frequency.

\section{Hardware Experimentation of Matrix Converter System}

The hardware realization of the proposed model is shown in Figure 15. The Code Composer Studio application is used for the real-time interface with the digital signal processor to produce the space vector algorithm based IGBT gate signals. 


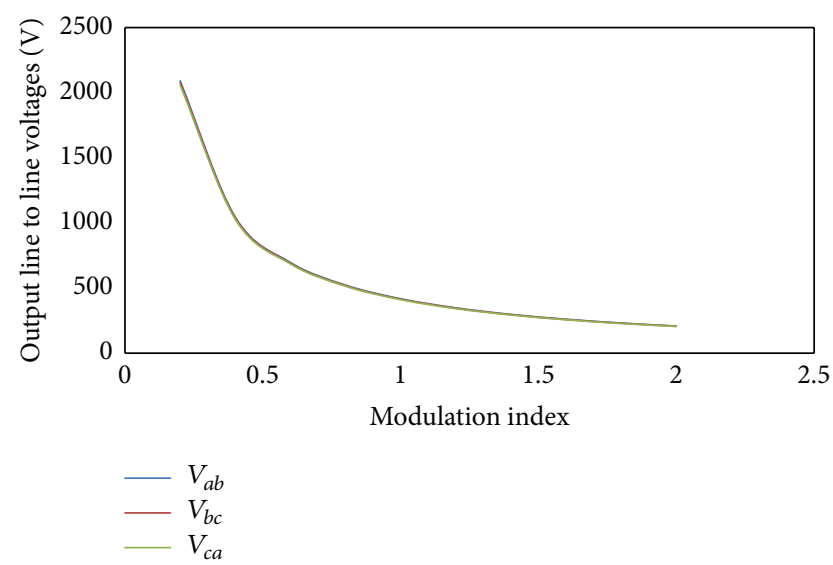

Figure 14: Modulation index characteristics at $200 \mathrm{~Hz}$ reference frequency.

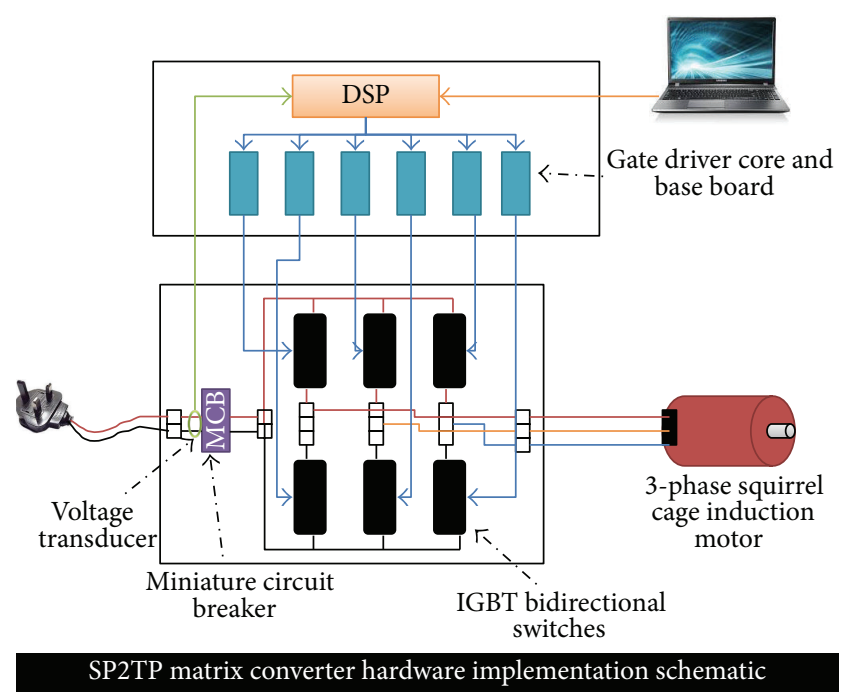

FIGURE 15: Hardware realization of matrix converter system.

The gate drive circuits and base board circuits are used to provide the appropriate gate voltages to the bidirectional switches. The developed hardware model is tested under different power factor loads.

Figure 16 shows the actual hardware experimental setup of the single-phase-to-three-phase matrix converter system. IGBT based bidirectional switches are used to design the matrix converter system. Texas Instrument DSP and the Concept IGBT Core Drives are used for the control operation. Synchronization circuit is used to synchronize the sinusoidal supply voltage with the control signals.

The RMS values of the practical hardware circuits are slightly lower than the simulation circuits. Figure 17 shows the practical line to line voltages compared with the simulation data. The variation is mainly due to the presence of odd harmonics in the hardware circuits.

Figure 18 shows the percentage total harmonic distortion (\%THD) of the $R$-phase voltage under unity power factor load condition for both simulation and practical readings.

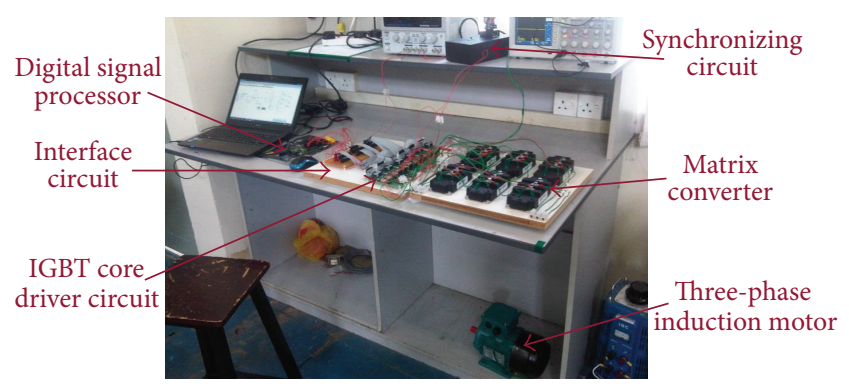

FIGURE 16: Hardware realization of matrix converter system.

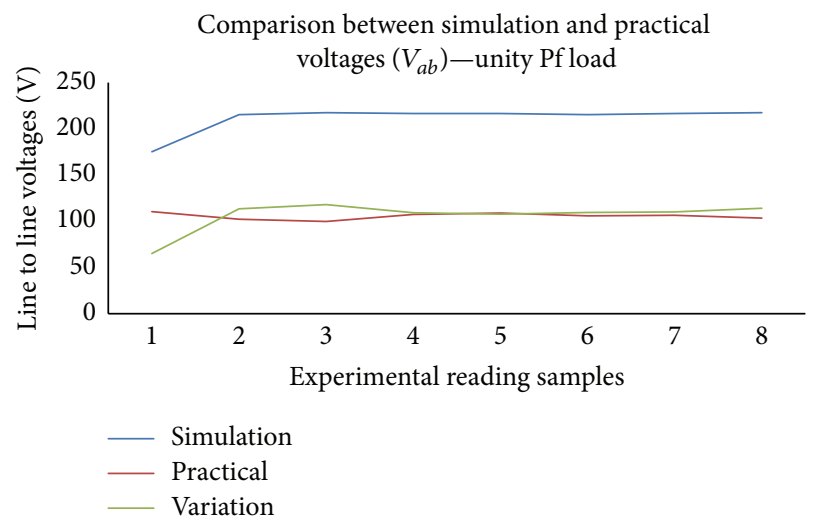

FIGURE 17: Comparison of simulation and practical line voltages.

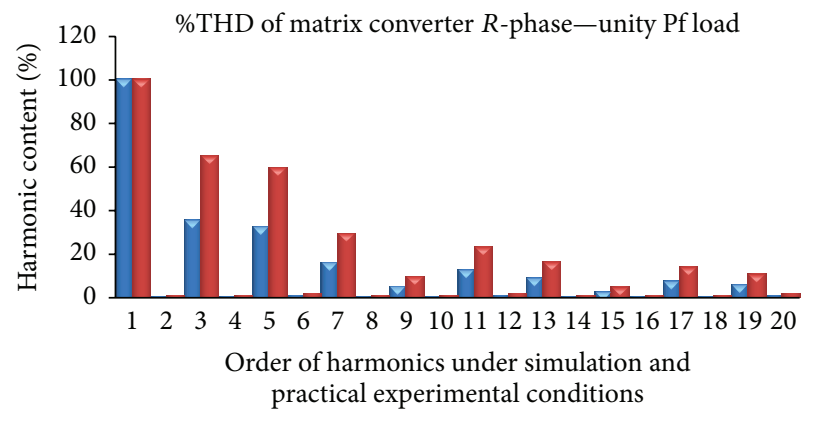

FIGURE 18: \% total harmonic distortion in the output voltage of matrix converter.

Only odd harmonics are found to be present and the practical $\% \mathrm{THD}$ is slightly higher compared to the simulation values. This is obvious due to the presence of odd harmonics.

\section{Conclusion}

Bidirectional switch based matrix converters are getting more popular due to their compact, convenient, and robust operation. State-of-the-art space vector PWM programming and switching techniques are employed in the gate triggering control of the matrix converters. The model was studied under different reference frequencies and modulation index conditions. The limitation of the proposed system is the unbalanced voltages produced due to odd harmonics presence. High harmonic contents are noticed which can be 
eliminated by incorporating proper filter circuits. Booster circuits also can be used to obtain the desired output voltage. The modulation characteristics are studied in view of obtaining the balanced three-phase output voltages. A significant behavior is noticed when the SP2TP matrix converter is operated above $150 \mathrm{~Hz}$ with appropriate modulation index; the output line to line voltages of the matrix converter are found to be balanced and differ by $120^{\circ}$ away from each other and exactly resemble the three-phase system. Adjustment has to be done at programming level to achieve the desired outcomes of the converter. The magnitudes of the output voltages can be varied using booster circuits. There are lots of scopes for enhancing the system design through further research for more stable and quality outputs.

\section{Conflict of Interests}

The authors declare that there is no conflict of interests regarding the publication of this paper.

\section{References}

[1] J. H. H. Alwash, "Predicting performance of three phase induction motors connected to single phase supplies," in IEE Proceedings on Electric Power Applications, vol. 143, no. 4, pp. 339-344, July 1996.

[2] M. R. Udayagiri and V. S. S. Sarma, "Single phase to three phase conversion without DC filter," in Proceedings of the IEEE International Symposium on Industrial Electronics, vol. 2, pp. 547-550, Xian, China, May 1992.

[3] V. Agarwal and S. Gupta, "An efficient algorithm for generalised single-phase converter," IET Power Electronics, vol. 3, no. 1, pp. 138-145, 2010.

[4] K. Zhou and D. Wang, "Relationship between space-vector modulation and three-phase carrier-based PWM: a comprehensive analysis [three-phase inverters]," IEEE Transactions on Industrial Electronics, vol. 49, no. 1, pp. 186-196, 2002.

[5] S. Kwak and H. A. Toliyat, "An approach to fault-tolerant threephase matrix converter drives," IEEE Transactions on Energy Conversion, vol. 22, no. 4, pp. 855-863, 2007.

[6] M.-K. Nguyen, Y.-G. Jung, Y.-C. Lim, and Y.-M. Kim, "A singlephase Z-source buck-boost matrix converter," IEEE Transactions on Power Electronics, vol. 25, no. 2, pp. 453-462, 2010.

[7] I. K. Shahidul, D. Z. Phoivos, and H. R. Muhammad, "Novel single- to three-phase static converter," IEEE Transactions on Industrial Applications, vol. 25, no. 1, pp. 143-152, 1989.

[8] M. H. El-Maghraby, R. H. Thejel, and M. M. Ibrahim, "New approach for the analysis of a three-phase induction motor of different ratings connected to a single-phase supply," IEE Proceedings B-Electric Power Applications, vol. 139, no. 3, pp. 145-154, 1992.

[9] J. Xiao, W. Zhang, H. Omori, and K. Matsui, "A novel operation strategy for single-to three-phase matrix converter," in Proceedings of the 12th International Conference on Electrical Machines and Systems (ICEMS '09), pp. 1-6, Tokyo, Japan, November 2009.

[10] J. W. Kolar, F. Schafmeister, S. D. Round, and H. Ertl, "Novel three-phase AC-AC sparse matrix converters," IEEE Transactions on Power Electronics, vol. 22, no. 5, pp. 1649-1661, 2007.
[11] K. Iino, K. Kondo, and Y. Sato, "An experimental study on induction motor drive with a single phase-three phase matrix converter," in Proceedings of the 13th European Conference on Power Electronics and Applications (EPE '09), pp. 1-9, Barcelona, Spain, September 2009.

[12] M. Imayavaramban, K. Latha, and G. Uma, "Analysis of different schemes of matrix converter with maximum voltage conversion ratio," in Proceedings of the 12th IEEE Mediterranean Electrotechnical Conference (MELECON '04), vol. 3, pp. 1137-1140, IEEE, Dubrovnik, Croatia, May 2004.

[13] H. Takahashi, R. Hisamichi, and H. Haga, "High power factor control for current-source type single-phase to three-phase matrix converter," in Proceedings of the IEEE Energy Conversion Congress and Exposition (ECCE '09), pp. 3071-3076, San Jose, Calif, USA, September 2009.

[14] M. Saito and N. Matsui, "A single- to three-phase matrix converter for a vector-controlled induction motor," in Proceedings of the IEEE Industry Applications Society Annual Meeting (IAS '08), pp. 1-6, IEEE, Edmonton, Canada, October 2008.

[15] M. R. Udayagiri and V. S. S. Sarma, "Single phase to three phase conversion without DC filter," in Proceedings of the IEEE International Symposium on Industrial Electronics (ISIE '92), Xian, China, May 1992.

[16] M. Saito, T. Takeshita, and N. Matsui, "A single to three phase matrix converter with a power decupling capability," in Proceedings of the IEEE 35th Annual Power Electronics Specialists Conference (PESC '04), pp. 2400-2405, IEEE, Aachen, Germany, June 2004.

[17] L. A. C. Lopes and M. F. Naguib, "Space vector modulation for low switching frequency current source converters with reduced low-order noncharacteristic harmonics," IEEE Transactions on Power Electronics, vol. 24, no. 4, pp. 903-910, 2009. 

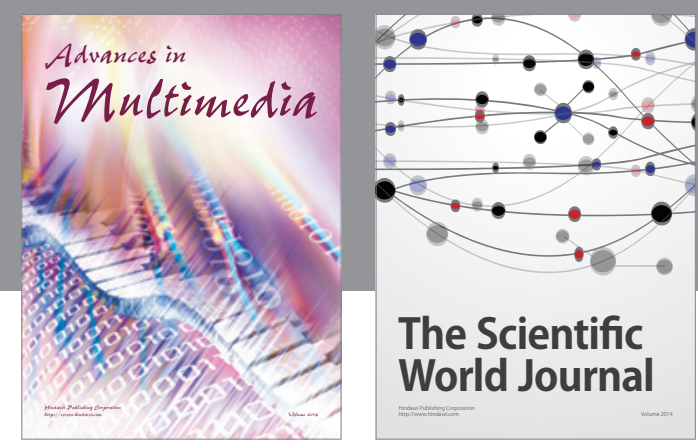

The Scientific World Journal
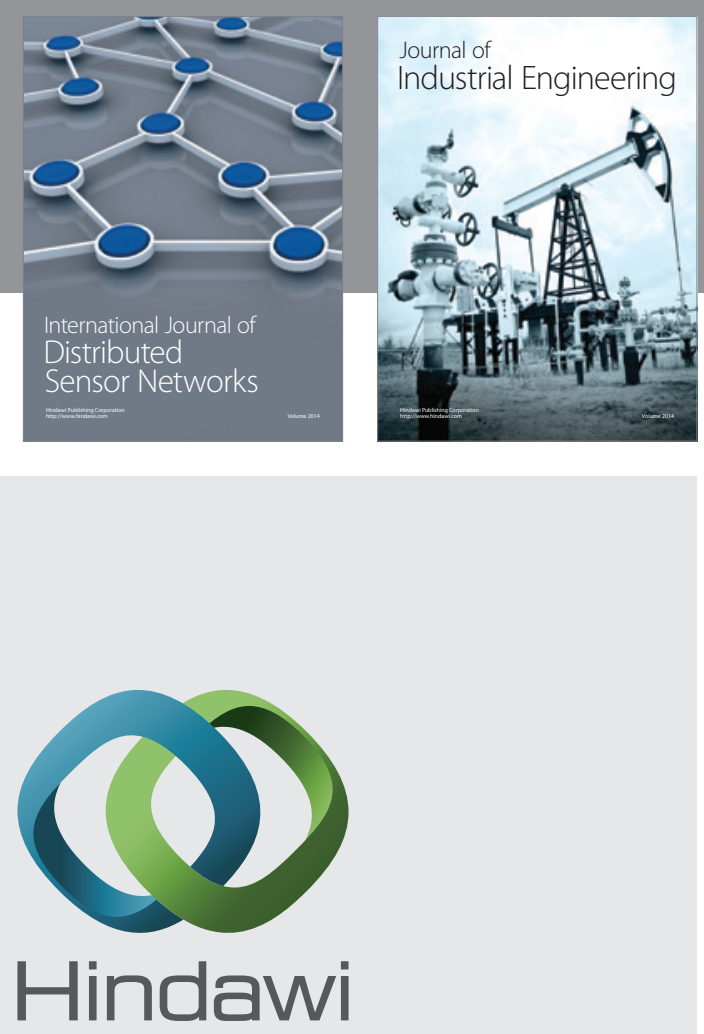

Submit your manuscripts at

http://www.hindawi.com

\section{Computer Networks} and Communications
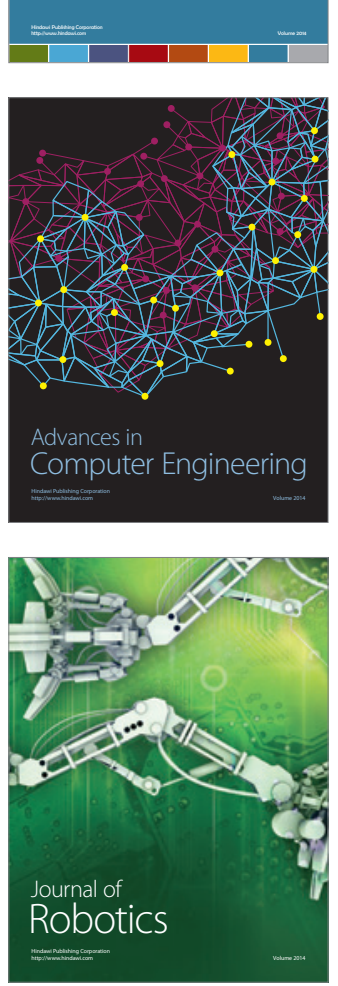
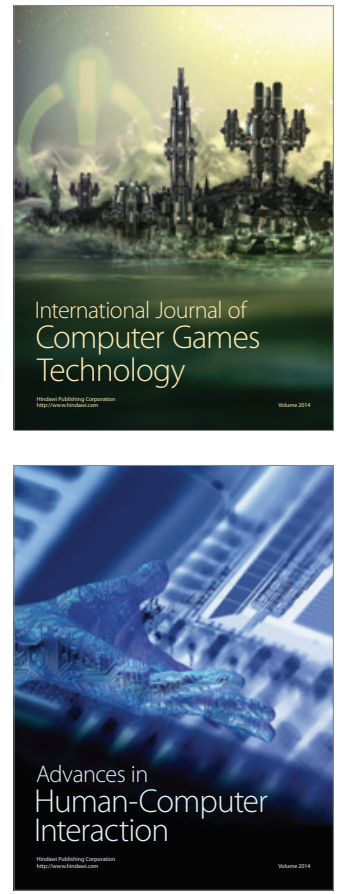
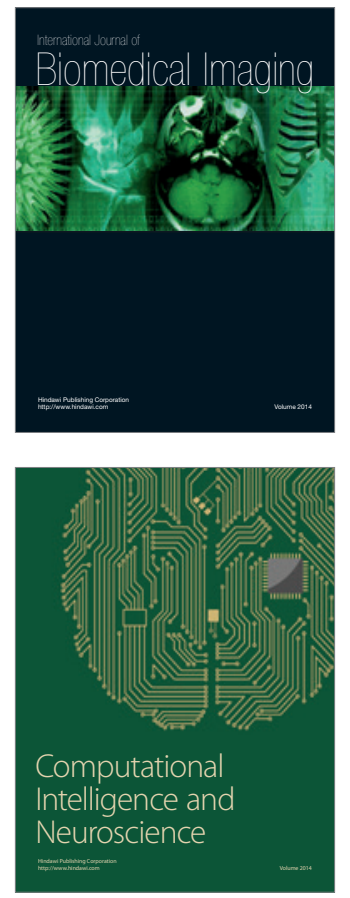
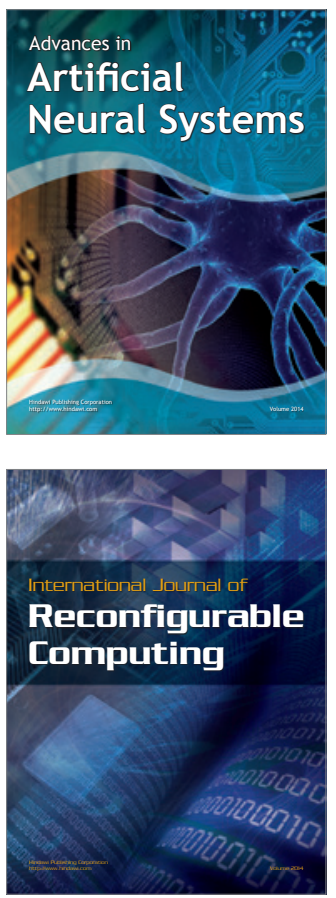
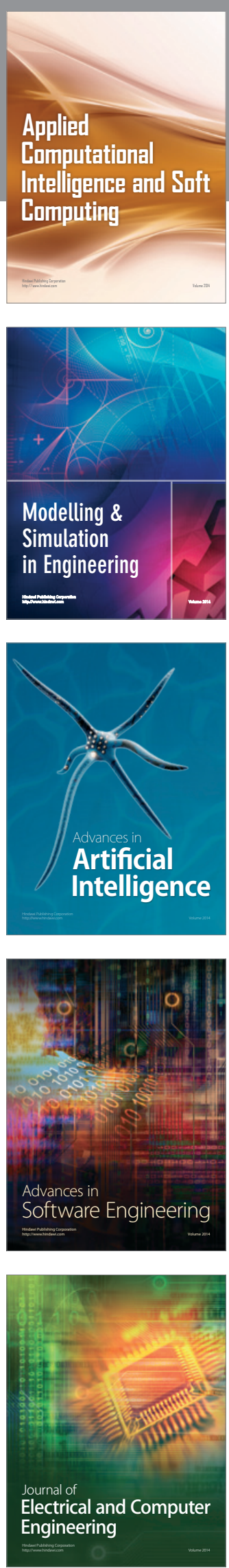